\title{
Spinal vascular malformations: an historical perspective
}

\author{
Perry Black, M.D. \\ Department of Surgery (Neurosurgery), Hahnemann University Hospital, \\ Drexel University College of Medicine, Philadelphia, Pennsylvania
}

\begin{abstract}
$\checkmark$ In this historical perspective, the author identifies three epochs in the development of the concepts and treatment of spinal vascular lesions: 1) early observations (1860s-1912), with the lesions during this time period recognized only at autopsy; 2) the "middle ages" (1912-1960), with surgical intervention sporadic and yielding dismal results; and 3) the modern era (beginning in the 1960s), coincident with parallel dramatic advances in radiology, microsurgical instrumentation, and anesthesiology. These advances resulted in a better understanding of the pathophysiological aspects and angioarchitecture of the lesions.

Whereas the nomenclature of the lesions in the past was confusing, a new understanding of these diseases that has emerged during the modern era has permitted refinement of the classification of the lesions as distinct biological entities. Modern diagnostic imaging has enabled identification of patients who may benefit from surgical or embolic occlusion, and treatment has become rationally based.

Future progress in the management of spinal vascular lesions may be anticipated, with improvement in noninvasive imaging for early detection of suspected abnormalities. Furthermore, advances in spinal cord neuroprotection may expand the range of future options for surgical or embolic intervention.
\end{abstract}

KEY WORDS • spine $\bullet$ spinal cord $\bullet$ arteriovenous malformation $\bullet$
arteriovenous fistula $\bullet$ aneurysm $\bullet$ history of neurosurgery

$\mathrm{T}$ HIS study was undertaken in an effort to trace the historical development of surgery for spinal vascular lesions. These lesions encompass AVMs, AVFs, spinal cord aneurysms, and vascular neoplasms of the spinal cord. Although these terms are incorrect in a strict sense, they are commonly used interchangeably. In the course of the study, attention was directed to the interplay of contributions from other disciplines, notably radiology, and surgical instrumentation such as the operating microscope (Fig. 1). Three time periods or epochs were identified: 1) early observations: 1860 s to $1912 ; 2$ ) the "middle ages": 1912 to 1960; and 3) the modern era: 1960 to the present. These three epochs are linked to the evolution of the classification of spinal vascular lesions (see Appendix).

\section{Early Observations: 1860s to 1912}

Based on autopsy material, Virchow ${ }^{22}$ (Fig. 2 left) provided the earliest classification of spinal vascular lesions, which he described as neoplasms. He distinguished two large groups: angioma cavernosum, in which there was an absence of parenchyma between the blood vessels; and angioma racemosum (hamartoma), in which vessels were separated by parenchyma.

The first clinical observation of a spinal vascular malformation occurred in Germany in 1890, and as described by Berenbruch, ${ }^{2}$ who operated on a patient with a spinal

Abbreviations used in this paper: $\mathrm{AVF}=$ arteriovenous fistula; $\mathrm{AVM}=$ arteriovenous malformation; $\mathrm{NIH}=$ National Institutes of Health. abnormality. The lesion was not identified as a vascular malformation at surgery, but it was subsequently recognized as a vascular abnormality at autopsy. In 1910, Fedor Krause $^{13}$ (Fig. 2 right) was the first to recognize a spinal lesion observed at laminectomy as a vascular abnormality. Krause did not attempt to resect the lesion, and there was no postoperative improvement.

\section{The "Middle Ages": 1912 to 1960}

The "middle ages" in the evolution of understanding and classification of spinal vascular lesions began in 1912 with Charles Elsberg (Fig. 3 left), who was the first to attempt to excise a spinal AVM. His patient was a 13-yearold boy who presented to the New York Neurological Institute with a 1-year history of bilateral thigh pain, followed by progressive spastic paraparesis and loss of bladder and bowel control. Elsberg related that "there was marked diminution of all three sensations over L2, L3, L4, L5, and S1 areas on both sides." Surgery was performed "for a suspected new growth." The following description is from Elsberg's ${ }^{9}$ operative report:

Laminectomy, January 20, 1912.... Removal of spines and laminae of 8th, 9th, 10th and 11th dorsal vertebrae, and incision of dura, exposed a large mass of tortuous blood vessels about 4 $\mathrm{cm}$. in length and fully $1 \mathrm{~cm}$. in thickness. Above, an artery and a vein, each 5 to $6 \mathrm{~mm}$. in width entered; below there were also two large vessels running down to the cauda blood supply, considerable bleeding occurred. Only part of the mass could be excised. No vessels appeared to come out of the cord itself, but there were a number of branches from the anterior surface of the cord. 


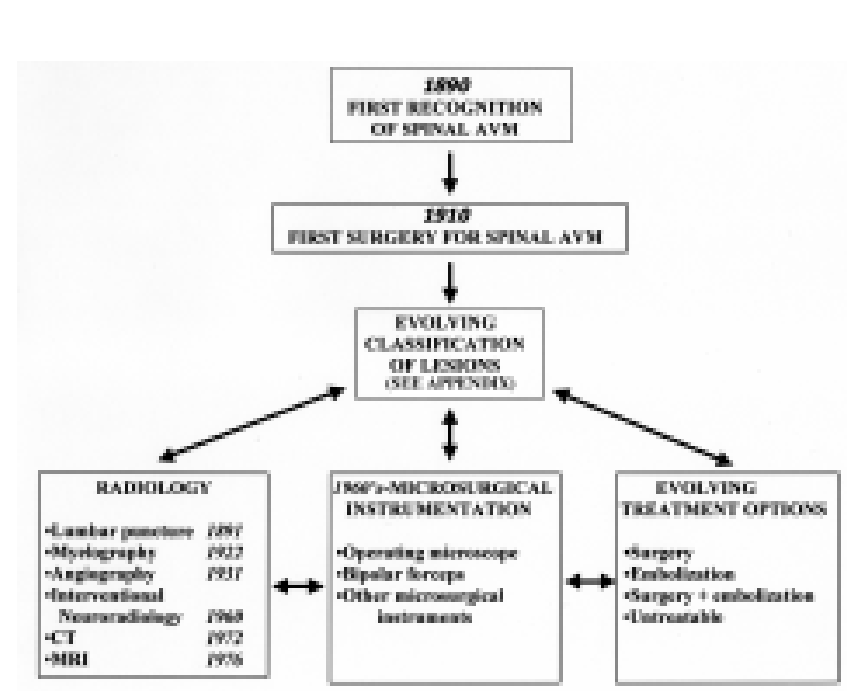

FIG. 1. Flow chart showing an overview of the historical evolution of developments in the early recognition of spinal vascular lesions up to the present. Parallel advances in radiology and in microsurgical instrumentation, beginning in the 1960s, are shown to interact with developments in the classification and treatment of spinal vascular lesions.

(The lesion described is similar to the drawing shown in Fig. 3 right.) Later in his book, Elsberg 9 reported the following: "Recovery from the operation was uneventful, but there was no improvement.... The condition was the same six months later." Elsberg's classification of spinal vascular lesions consisted of three categories: aneurysm, angioma, and dilation of veins (see Appendix).

Between 1912 and 1960, there were sporadic attempts to treat spinal AVMs surgically, but in the absence of a clear understanding of the vascular anatomy and the pathophysiological features of the lesions, lack of spinal vascular imaging, and with microneurosurgery yet to be developed, the clinical outcomes were generally dismal.

In their monograph published in 1928, Cushing and Bailey ${ }^{5}$ devoted their attention briefly to spinal vascular lesions. They categorized these entities as neoplasms and as

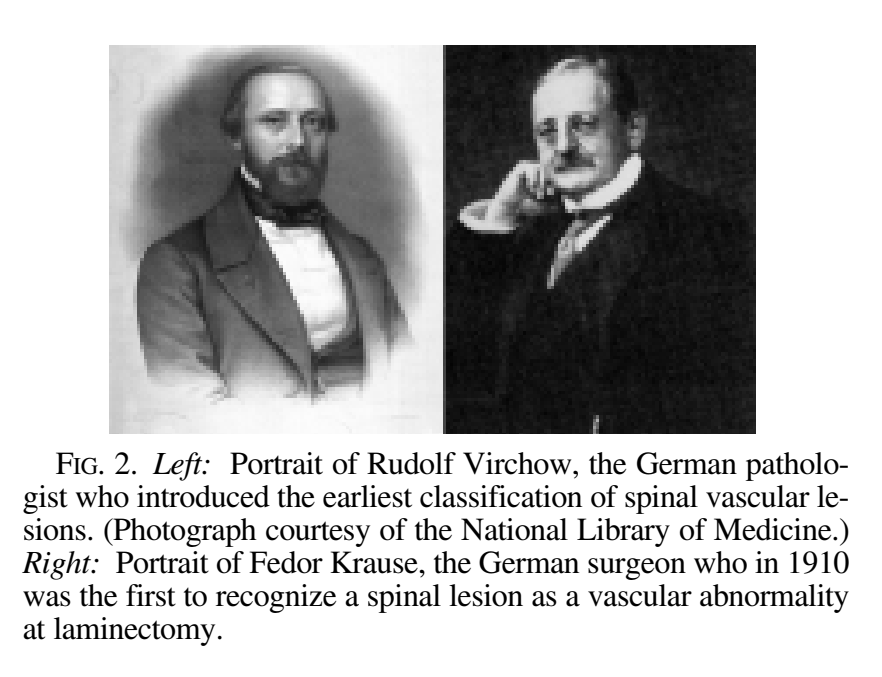

vascular malformations, with the latter including a plexus of dilated veins, aneurysmal varix, venous angioma, and telangiectasis. Some years later, in 1936, Bergstrand et al. ${ }^{4}$ presented their classification of spinal vascular lesions. It was quite similar to that of Cushing and Bailey. In the early 1940s, Wyburn-Mason ${ }^{23}$ classified spinal vascular lesions in one of the following groups: 1) venous malformations; 2) AVMs; or 3) "true tumors" (see Appendix). Although his system was useful in pathological terms, WyburnMason's classification, like those of his predecessors, was of limited value in terms of advancing clinical management. It was not until the 1960s that parallel developments in radiology, anesthesiology, and microsurgical instrumentation (Fig. 1) permitted the emergence of what might be viewed as the modern era.

\section{The Modern Era: 1960 to the Present}

Initiated in Sweden in the 1960s, subspecialization in neuroradiology rapidly spread to the US, England, France, and other countries. This subspecialization led to the emergence of interventional neuroradiology, which was essential for the development of precise imaging techniques

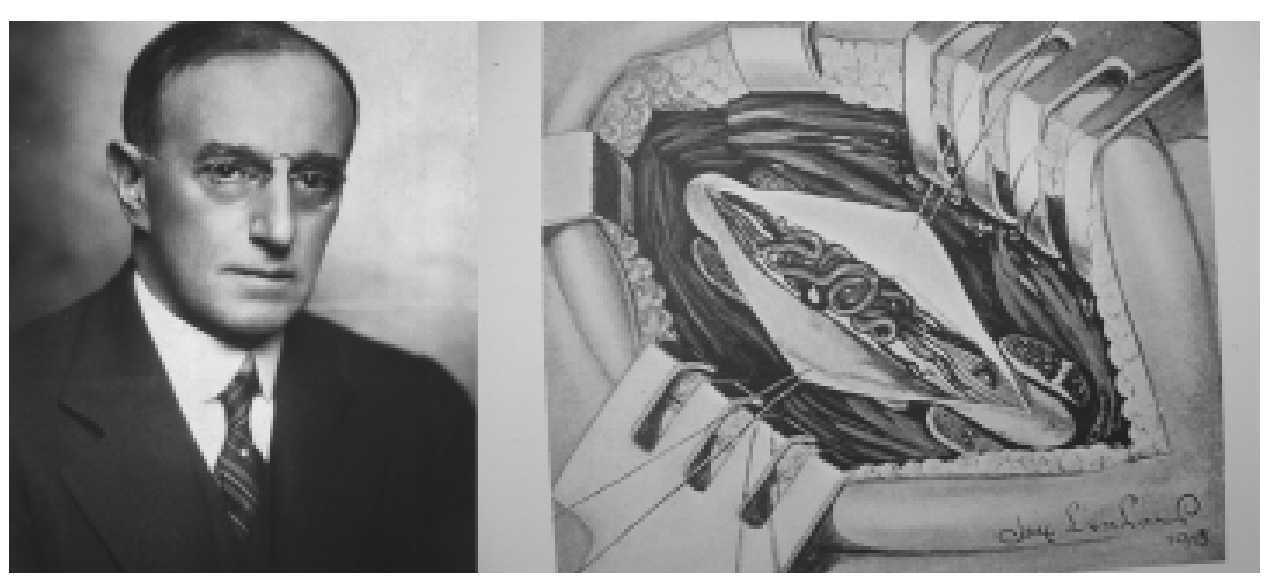

FIG. 3. Left: Portrait of Charles Elsberg, a neurosurgeon at the New York Neurological Institute and at Mount Sinai Hospital, who was the first to attempt to excise a spinal AVM in 1912. (Photograph courtesy of the National Library of Medicine.) Right: Artist's drawing of a lesion captioned “Aneurysms of posterior spinal vessels." Reprinted with permission from Elsberg CA: Diagnosis and Treatment of Surgical Diseases of the Spinal Cord and Its Membranes. Philadelphia: WB Saunders, 1916.) 


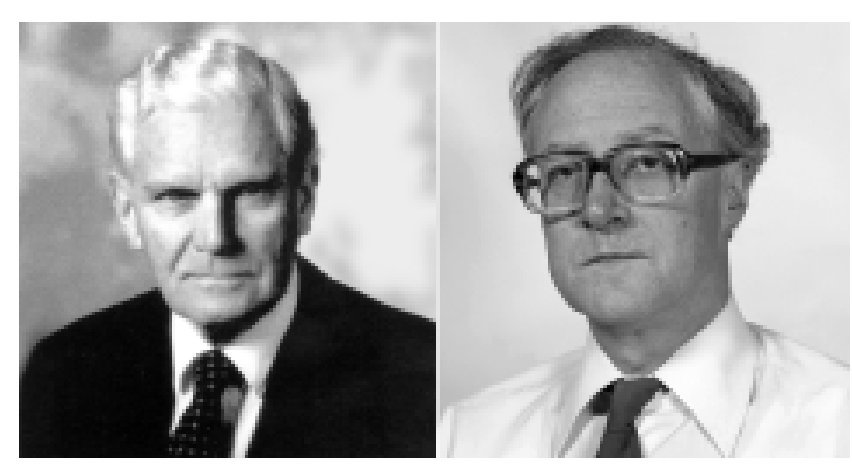

FIG. 4. Left: Portrait of Valentine Logue, the neurosurgeon who, along with neuroradiologist Brian Kendall and associate M. J. Aminoff, was a member of the English contingent of the "American/English/French connection" in introducing the modern era in the understanding and treatment of spinal vascular lesions (see also Fig. 7). (Photograph courtesy of the University College of London Institute of Neurology.) Right: Portrait of Brian Kendall, the neuroradiologist at the Institute for Neurology and Neurosurgery, Queen Square, London, who worked with Valentine Logue and A. M. Aminoff in the 1960s and 1970s. Together they studied the pathophysiology and clinical aspects of spinal vascular abnormalities. (Photograph courtesy of the University College London Institute of Neurology.)

for spinal vascular lesions. The intrathecal metrizamide computed tomography myelogram was introduced as a diagnostic screening test. Selective spinal angiography became the definitive diagnostic tool for evaluating spinal AVMs. ${ }^{6}$ Embolization of vascular lesions added a further dimension to treatment options.

Also in the 1960s, the introduction of the operating microscope, ${ }^{8}$ the development of microsurgical instruments, including bipolar forceps (invented by Greenwood in $1940^{10}$ and subsequently refined by Malis ${ }^{15}$ ), and progress in anesthesiology empowered neurosurgeons to undertake procedures that were previously thought to be

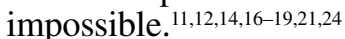

The advances in interventional neuroradiology and

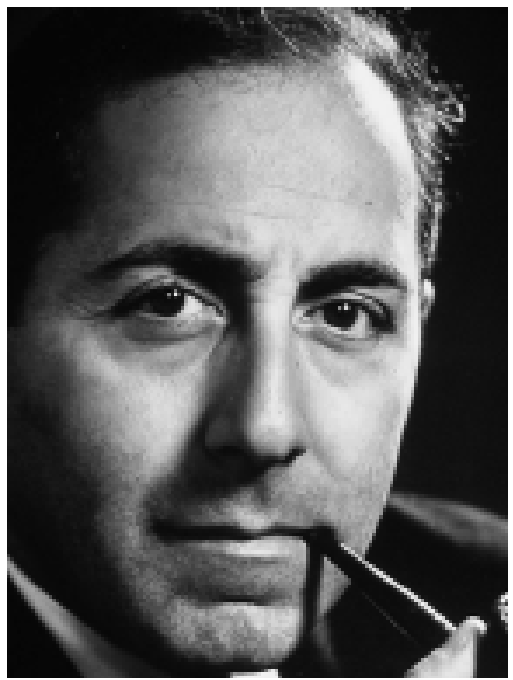

FIG. 5. Portrait of René Djindjian, a pioneer French neuroradiologist of Armenian descent, who made major contributions to selective spinal angiography at Hôpital Lariboisière in Paris. Djindjian led the French contingent of the "American/English/French connection" in pursuit of unraveling the enigma of spinal vascular malformations (see also Fig. 7). (Photograph courtesy of Professor Emmanuel Houdart.)

microneurosurgery allowed detailed evaluations that enhanced understanding of the vascular anatomy as well as the pathophysiological features of the vascular lesions. For example, in 1977 Kendall and Logue ${ }^{12}$ demonstrated that lesions formerly thought to be venous angiomas on the surface of the spinal cord were actually normal veins dilated by communication with arterial blood from a dural AVF. It was further observed that the pathophysiological mechanism of most spinal AVMs is associated with venous hypertension. It was shown that, in many cases, the irregular vascular pattern seen on myelography and at surgery represented arterialized draining veins, rather than the AVM itself. ${ }^{1}$

The remarkable strides that occurred in neuroimaging

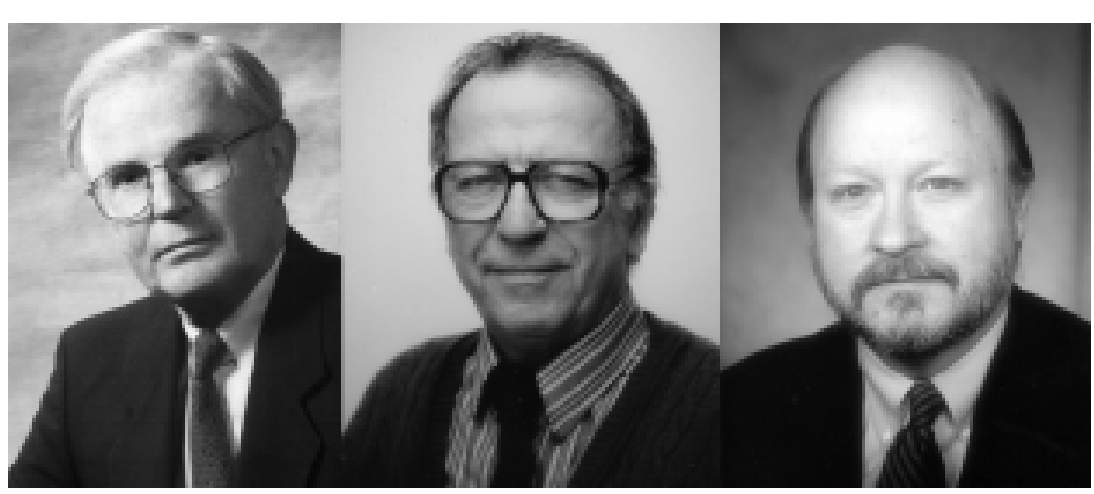

FIG. 6. Left: Portrait of the neuroradiologist John Doppman, a leading member of the American team at the NIH in Bethesda, Maryland. Doppman and colleagues Giovanni Di Chiro, Ayub Ommaya, and Edward Oldfield were the American contingent of the "American/English/French connection" (see also Fig. 7). (Photograph courtesy of Anne Marie Doppman.) Center: Portrait of the radiologist Giovanni Di Chiro, a major contributor to the effort at the NIH. (Photograph courtesy of Barbara and Giovanna Di Chiro.) Right: Portrait of Edward Oldfield, who, along with neurosurgical colleague Ayub Ommaya, collaborated with radiologists John Doppman and Giovanni Di Chiro at the NIH from the 1960 s to the $1980 \mathrm{~s}$ 


\section{THE AMERICAN / ENGLISH / FRENCH CONNECTION}

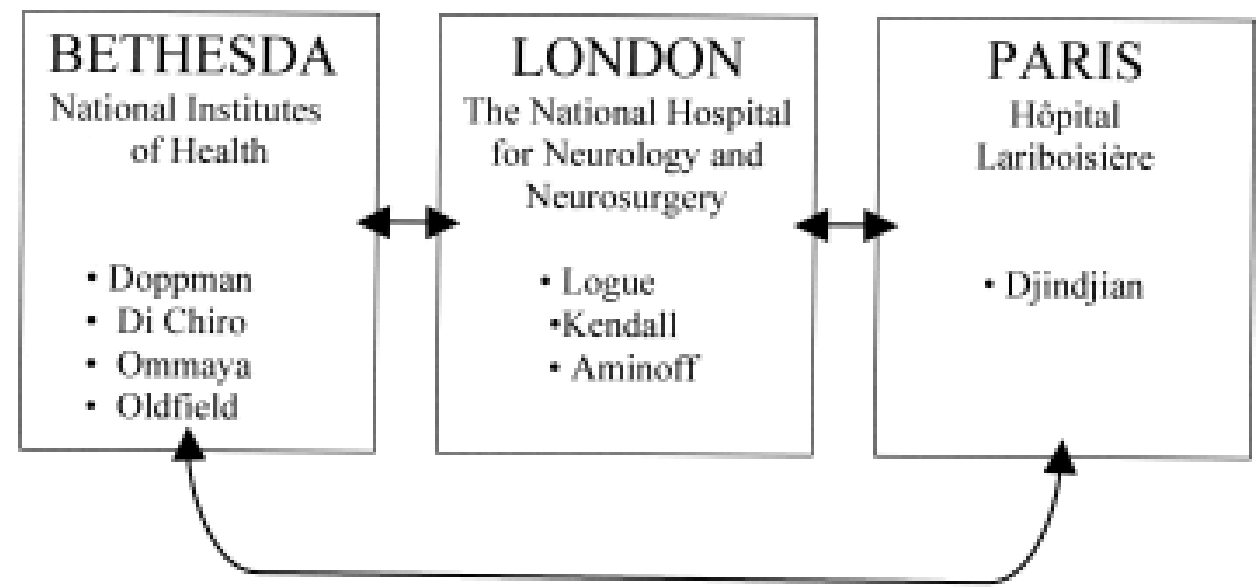

FIG. 7. Chart depicting three centers in England, France, and the US, each actively pursuing studies on spinal vascular disorders from the 1960s through the 1980s. Although the three centers worked independently, there was considerable intellectual interaction, with their combined effort resulting in significant contributions to the understanding of the angioarchitecture, pathophysiological mechanisms, and treatment of spinal vascular lesions.

and in surgical technique resulted in a better understanding of the angioarchitecture and pathology of the lesions, which likewise enhanced clarity in classification of these entities. From the 1960s through the 1980s, major new and clinically useful insights emerged; these were largely the product of a collaborative effort among neuroradiologists and neurosurgeons in England, France, and the US. In England, neurosurgeon Valentine Logue (Fig. 4 left) worked with neuroradiologist Brian Kendall (Fig. 4 right) and with an associate, M. J. Aminoff, at the National Hospital for Neurology and Neurosurgery in London..$^{1,12}$ In France, the driving force was neuroradiologist René Djindjian (Fig. 5) at Hôpital Lariboisière in Paris. ${ }^{7}$ In the US, the key center of spinal vascular activity was at the
NIH in Bethesda, Maryland, where neuroradiologist John Doppman (Fig. 6 left) was a leading member of the NIH team, along with radiologist Giovanni Di Chiro (Fig. 6 center), and neurosurgeons Ayub Ommaya and Edward Oldfield (Fig. 6 right). Although the three centers worked independently of each other, there was considerable intellectual interaction at the personal level as well as through their respective publications.

The three transcontinental centers - the vanguard of the modern era-can be viewed as the "American/English/ French connection" in terms of their combined effort in generating new insights concerning the angioarchitecture, pathophysiology, and treatment of spinal vascular lesions (Fig. 7). Their contributions led to the following classifi-

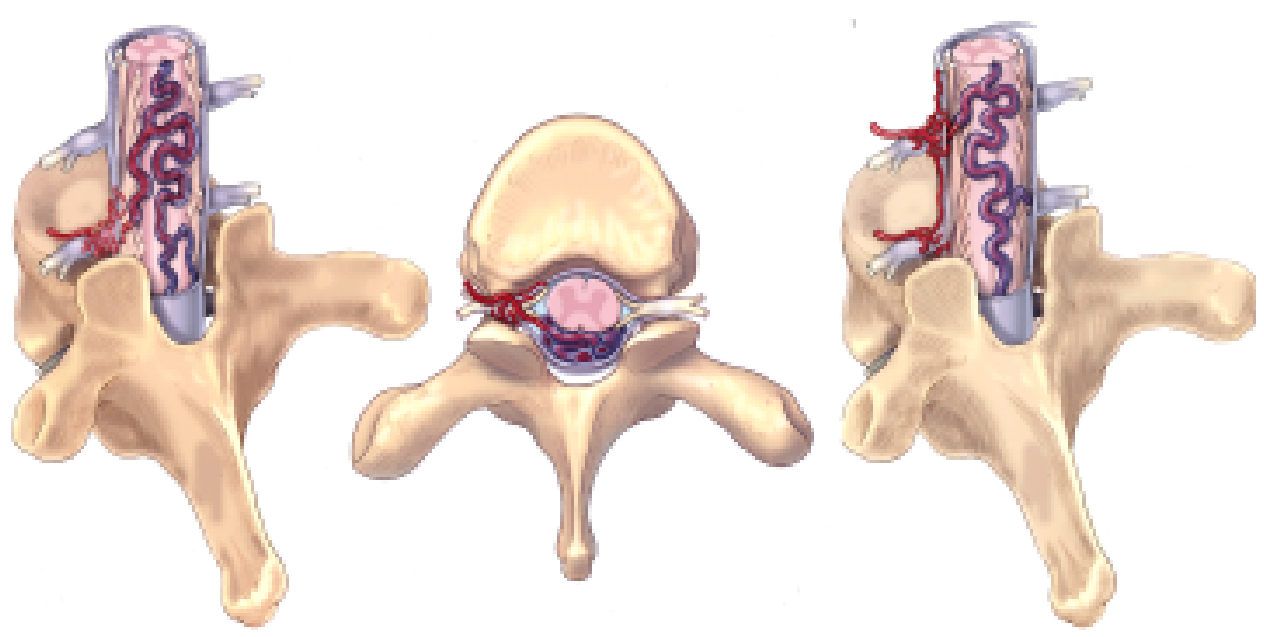

FIG. 8. Artist's drawing of an intradural dorsal spinal AVF. Dural AVFs represent the majority of spinal vascular abnormalities. The intradural lesion shown here may be treated surgically by coagulation and transsection; those that are extradural may be effectively embolized. Reprinted with permission from Spetzler RF, Detwiler PW, Riina HA, Porter RW: Modified classification of spinal cord vascular lesions. J Neurosurg (Spine 2) 96:145-156, 2002. 


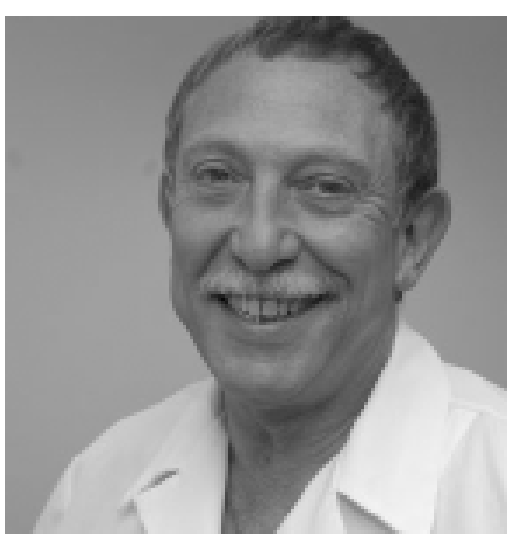

FIG. 9. Portrait of Alex Berenstein, a neuroradiologist who practiced at St. Luke's Roosevelt Hospital and at Beth Israel Hospital in New York City; he became a leading interventional specialist.

cation, which consists of four types of lesions: Type I, dural AVFs (Fig. 8); Type II, glomus AVMs; Type III, juvenile AVMs; and Type IV, direct spinal AVFs (this type was introduced by Heros et al. ${ }^{11}$; see Appendix).

As the pathophysiological mechanisms and spinal vascular anatomy became better understood, a number of talented practitioners brought the new therapeutic procedures into popular use. Among these were neuroradiologist Alex Berenstein $^{3}$ (Fig. 9) of New York City and a Swiss neurosurgeon of Turkish descent, Gazi Yaşargil (Fig. 10 left), who learned microneurosurgical technique in the laboratory of the pioneer microneurosurgeon R. M. Peardon Donaghy (Fig. 10 right) at the University of Vermont in Burlington, Vermont. In the earlier years of the modern era, neurosurgeon Leonard Malis (Fig. 11) of New York City, among others, developed considerable surgical experience with spinal vascular disorders and taught the techniques to his residents and to practicing neurosurgeons.

In 2002, based on their experience with a large number of surgically treated cases of spinal vascular anomalies, clinicians at Hôpital Bicêtre ${ }^{16}$ in France offered a classification with two broad categories: AVMs and AVFs. In addition, a genetic classification of arteriovenous shunts was proposed. In the same year that the Bicêtre classification was proposed, Spetzler and his coworkers ${ }^{21}$ advanced a modification of the popular designation of Types I through IV, and they added neoplastic vascular lesions to their simplified nomenclature for purely vascular lesions: aneurysms and arteriovenous lesions (with subcategories); they also introduced AVMs of the conus medullaris as a new category of AVM (see Appendix).

Because diagnostic techniques and treatment options have significantly improved since the 1960s, it is now possible to identify patients for whom successful surgical or embolic occlusion can be expected. Modern diagnostic imaging likewise enables us to identify those with extensive involvement of the spinal cord, for whom neither surgical nor embolic treatment is feasible. ${ }^{14-21}$

\section{Discussion}

In the nineteenth century, when spinal vascular lesions were first identified, these were thought to be tumors. It was then recognized that vascular neoplasms and purely vascular malformations were distinctly separate entities. The subject was further clouded by the confusing nomenclature, as stated by Wyburn-Mason: "one name being used to indicate two or more pathological conditions, and, conversely, a single pathological condition being designat-

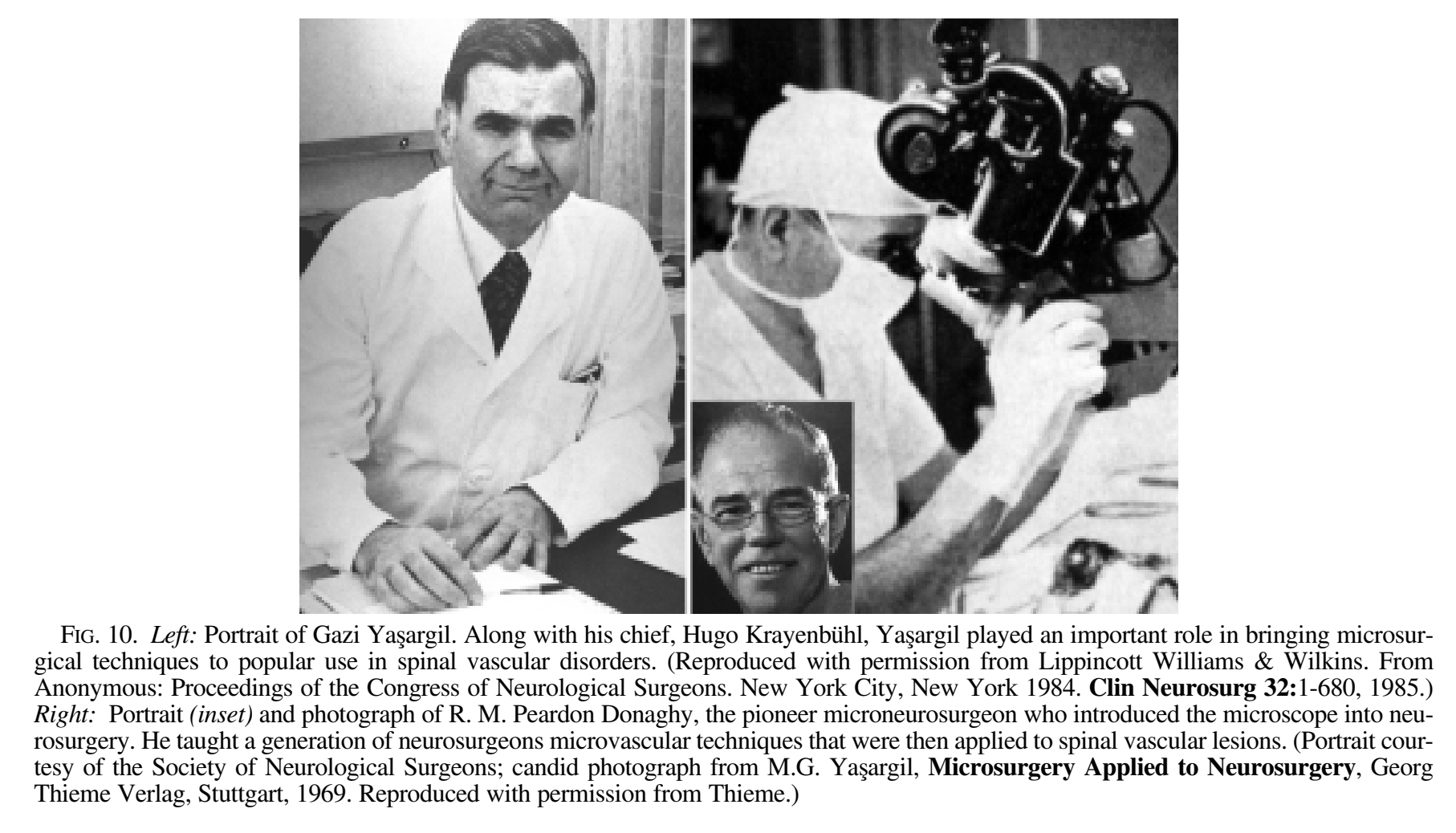




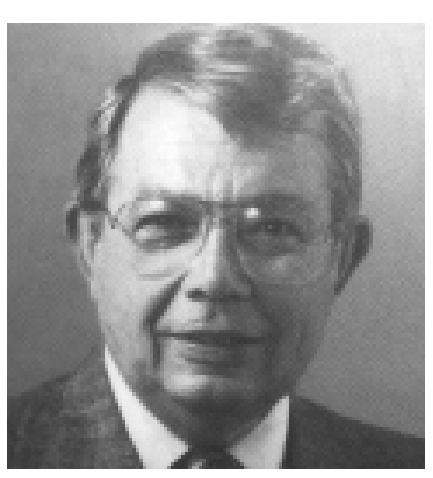

FIG. 11. Portrait of Leonard Malis, of Mount Sinai Hospital in New York City, who made important contributions to microneurosurgery, with his refinement of Greenwood's original (1940) bipolar coagulator and introduction of video through the microscope. Malis gained considerable experience with surgery for spinal vascular disorders, developing techniques that he taught to his residents and to practicing neurosurgeons. (Photograph courtesy of the Society of Neurological Surgeons.)

ed by different names." ${ }^{23}$ Some systems excluded neoplasms, whereas a recent classification by Spetzler et al. ${ }^{21}$ reincorporates vascular neoplasms. Furthermore, recent classifications have a clearly defined nomenclature.

In tracing the historical landmarks in the evolution of the concepts of vascular lesions, I have identified three epochs in this paper: 1) a period of early observations between the 1860s and 1912, in which the nature of the spinal lesion was recognized only at autopsy; 2 ) the "middle ages," from 1912 to 1960, during which surgical intervention was undertaken only sporadically and with dismal results; and 3) the modern era, beginning in the 1960s, which coincided with parallel dramatic advances in radiology, microsurgical instrumentation, and anesthesiology. These advances resulted in an improved understanding of the pathophysiological features and angioarchitecture of the lesions. These developments enabled classification of the lesions as biologically distinct entities.

Progress in radiological diagnostic techniques, surgical instrumentation, and pathophysiological mechanisms of the lesions flourished in a number of countries from the 1960s through the 1980s, especially in England, France, and the US. The three transcontinental centers- the vanguard of the modern era-can be viewed as the "American/English/French connection" in terms of their combined effort in generating new insights concerning the angioarchitecture, pathophysiological features, and treatment of spinal vascular lesions. In each of these three countries, a team of neuroradiologists working in collaboration with neurosurgeons was able to focus on the spinal AVM "project" as a result of sustained government support.

Future progress in the management of spinal vascular lesions can be anticipated, with improvement in early noninvasive detection of malformations in patients in whom a vascular lesion is suspected. One consideration would be refinements in the quality of magnetic resonance imaging. Further advances in spinal cord neuroprotection (such as local cord cooling) may expand the range of surgical or embolic intervention.

\section{Appendix \\ Evolving classification of spinal vascular lesions}

Virchow (1858)

Vascular Tumors

I. Angioma cavernosum (absence of parenchyma between the blood vessels)

II. Angioma racemosum (hamartoma-vessels separated by parenchyma)

-telangiectasis (thin-walled vessels like capillaries)

-angioma racemosum arteriale sive venosum (vascular walls suggest arteries or veins; blood may shortcut artery to vein: arteriovenous aneurysm)

\section{Elsberg (1916)}

Three Categories of Spinal Vascular Abnormalities

I. Aneurysm of spinal vessels

II. Angioma in which a mass of dilated veins penetrates the spinal cord

III. Dilation of posterior spinal veins ("hemorrhoids" of the spinal pia mater)

\section{Hemangioblastomas} Cushing \& Bailey (1928)

-vascular neoplasms of spinal cord (blood vessels and network of reticulum)

II. Vascular malformations

a. plexus of dilated veins

b. aneurysmal varix

c. venous angioma

d. telangiectasis

e. venous angioma or telangiectasis may develop an "aneurysm by anastomosis" (arteriovenous communication)

\section{Bergstrand, Olivecrona, Tönnis (1936)}

I. Angioma cavernosum (no neural tissue between the vessels)

II. Angioma racemosum venosum

III. Arteriovenous aneurysm

IV. Hemangioblastoma

V. Telangiectasis

\section{A. Abnormalities \\ Wyburn-Mason (1944)}

I. Venous abnormalities

a. secondary venous abnormalities occurring below a tumor of the spinal cord, or associated with arachnoiditis or calcification of the cord

b. angioma racemosum venosum (extensive venous varicosities affecting the pia and central regions of the spinal cord)

II. Arteriovenous angioma

III. Arterial anomalies

a. associated with congenital heart disease

b. alone

IV. Syphilitic aneurysm of the spinal arteries

V. Telangiectases, including so-called cavernomas or cavernous angiomata

B. True tumors

VI. Hemangioblastoma or hemangioendothelioma

a. angioreticuloma, or Landau tumor (in spinal cord or on a nerve root, and may be associated with syringomyelia or with similar tumors elsewhere in the nervous system and cysts in other organs)

b. extradural hemangioblastoma

VII. Lymphangioma

The "American/English/French Connection":

Di Chiro, Doppman, Ommaya (1967); Djindjian (1975);

Kendall \& Logue (1977); Oldfield, Di Chiro, Quindlen, Rieth,

Doppman (1983); Heros, Debrun, Ojemann, Lasjaunias, Naessens (1986)

Type I. Dural (intradural or extradural) AVF (also referred to as 
Type I spinal AVM or as "angioma racemosum venosum," nidus, or true AVM), usually in the dural sleeve of a spinal root, associated with a single-coiled vessel on dorsal pial surface of the spinal cord

Type II. Glomus AVMs

Type III. Juvenile AVMs (nidus usually intramedullary)

Type IV. Direct spinal AVF (thought to be first recognized in 1986 [Heros et al. $\left.{ }^{11}\right]$ ); these abnormalities are direct fistulas between the blood supply of the spinal cord (usually the anterior spinal artery) and a vein, resulting in aneurysmal dilation of the draining veins

Hôpital Bicêtre:

Rodesch, Hurth, Alvarez, Tadie, Lasjaunias (2002)

\section{A. AVMs}

B. Fistulae (micro- or macrofistulae)

C. Genetic classification of spinal cord arteriovenous shunts

a. genetic hereditary lesions (macrofistulae and hereditary hemorrhagic telangiectasia)

b. genetic nonhereditary lesions (multiple lesions with metameric or myelomeric associations)

c. single lesions (incomplete associations of categories a or b)

Spetzler, Detwiler, Riina, Porter (2002)

Three Broad Categories

1. Neoplastic vascular lesions

a. hemangioblastoma

b. cavernous malformation

2. Spinal aneurysms (occur rarely)

3. Arteriovenous lesions

a. AVFs

-extradural

-intradural (dorsal or ventral)

b. AVMs

-extradural-intradural

-intradural

-intramedullary

-intramedullary-extramedullary

-conus medullaris

\section{Acknowledgments}

I am grateful to the following individuals for their help in the preparation of this paper: my wife, Phyllis Black, M.S.W., Ph.D.; my secretary, Tricia Grey, B.A.; J.B. Harrington, B.A. (Philadelphia, PA); Jahangir Maleki, M.D., Ph.D. (Philadelphia, PA); Emily Morton (Philadelphia, PA); Rebecca Raszewski, M.S. (Reference Librarian, Drexel University, Philadelphia, PA); George David Anderson (Washington, DC); Alex Berenstein, M.D. (New York, NY); Barbara Di Chiro (Bethesda, MD); Giovanna Di Chiro, Ph.D. (South Hadley, MA); Jacques Dion, M.D. (Toronto, Ontario, Canada); Anne Marie Doppman (Potomac, MD); Jaime Hoffman (Phoenix, AZ); Professor Emmanuel Houdart (Paris, France); M.E. Jensen, M.D. (Charlottesville, VA); Ferenc A. Jolesz, M.D. (Boston, MA); George Kaim (London, England); Brian Kendall, F.R.C.P., F.R.C.S., F.R.C.R. (London, England); Pierre Lasjaunias, M.D., Ph.D. (Paris, France); Marie Miller (Washington, D.C.); Edward Oldfield, M.D. (Bethesda, MD); and Professor Luc Picard (Nancy, France).

\section{References}

1. Aminoff MJ, Barnard RO, Logue V: The pathophysiology of spinal vascular malformations. J Neurol Sci 23:255-263, 1974

2. Berenbruch K: Ein fall von multiplen Angio-Lipomen Kombiniert mit einem angiom des Rückenmarks, Doctoral thesis, Universität Tübingen, 1890

3. Berenstein A, Young W, Ransohoff J, Benjamin V, Merkin H: Somatosensory evoked potentials during spinal angiography and therapeutic transvascular embolization. J Neurosurg 60: 777-785, 1984

4. Bergstrand $\mathrm{H}$, Olivecrona $\mathrm{H}$, Tönnis $\mathrm{W}$ : Gefässmissbildungen und Gefässgeschwülste des Gehirns. Leipzig: Georg Thieme, 1936, pp 32-43

5. Cushing H, Bailey P: Tumors Arising from the Blood-Vessels of the Brain. Angiomatous Malformations and Hemangioblastomas. Springfield, IL: Charles C Thomas, 1928, pp 3-8

6. Di Chiro G. Doppman JL, Ommaya AK: Selective arteriography of arteriovenous aneurysms of spinal cord. Radiology 88: 1065-1077, 1967

7. Djindjian R: Embolization of angiomas of the spinal cord. Surg Neurol 4:411-420, 1975

8. Donaghy RMP, Yaşargil MG (eds): Microvascular Surgery. Stuttgart: Georg Thieme Verlag, 1967

9. Elsberg CA: Diagnosis and Treatment of Surgical Diseases of the Spinal Cord and Its Membranes. Philadelphia: WB Saunders, 1916, pp 194-204

10. Greenwood J Jr: Two point coagulation. A new principle and instrument for applying current in neurosurgery. Am J Surg 50:267-270, 1940

11. Heros RC, Debrun GM, Ojemann RG, Lasjaunias PL, Naessens PJ: Direct spinal arteriovenous fistula: a new type of spinal AVM. Case report. J Neurosurg 64:134-139, 1986

12. Kendall BE, Logue V: Spinal epidural angiomatous malformations draining into intrathecal veins. Neuroradiology 13: 181-189, 1977

13. Krause F: [Surgery of the Brain and Spinal Cord: Based on Personal Experiences.] New York: Rebman, 1912 (Ger) (Haubold HA, transl.)

14 Krayenbuhl H, Yaşargil MG, McClintock HG: Treatment of spinal cord vascular malformations by surgical excision. J Neurosurg 30:427-435, 1969

15. Malis L: Bipolar coagulation in microsurgery, in Yaşargil MG (ed): Microsurgery Applied to Neurosurgery. Stuttgart: Georg Thieme, 1969, pp 41-45

16. Malis LI: Microsurgery for spinal cord arteriovenous malformations. Clin Neurosurgery 26:543-555, 1979

17. Ojemann RG, Ogilvy CS, Heros RC, Crowell RM: Surgical Management of Cerebrovascular Disease, ed 2. Baltimore: Williams and Wilkins, 1988, pp 451-466

18 Oldfield EH: Spinal vascular malformations, in Wilkins RH, Rengachary SS (eds): Neurosurgery, ed 2. New York: McGraw-Hill, 1996, Vol 2, pp 2541-2558

19. Oldfield EH, Di Chiro G, Quindlen EA, Rieth KG, Doppman JL: Successful treatment of a group of spinal cord arteriovenous malformations by interruption of dural fistula. J Neurosurg 59:1019-1030, 1983

20. Rodesch G. Hurth M, Alvarez H, Tadie M, Lasjaunias P: Classification of spinal cord arteriovenous shunts: proposal for a reappraisal-the Bicêtre experience with 155 consecutive patients treated between 1981 and 1999. Neurosurgery 51: 374-380, 2002

21 Spetzler RF, Detwiler PW, Riina HA, Porter RW: Modified classification of spinal cord vascular lesions. J Neurosurg 96 (2 Suppl):145-156, 2002

22. Virchow R: Die Krankhaften Geschwülste. Berlin: A Hirschwald, 1864-1865, pp 456-463

23. Wyburn-Mason R: The Vascular Abnormalities and Tumours of the Spinal Cord and its Membranes. St. Louis: CV Mosby, 1943, pp 1-5

24. Yaşargil MG: Surgery of vascular lesions of the spinal cord with the microsurgical technique. Clin Neurosurg 17: 257-265, 1970

Manuscript received August 11, 2006.

Accepted in final form November 17, 2006.

Address reprint requests to: Perry Black, M.D., Hahnemann University Hospital, Drexel University College of Medicine, New College Building, 7th Floor, Mail Stop 413, 245 North 15th Street, Philadelphia, Pennsylvania 19102. email: pblack@drexelmed.edu. 